\title{
Red Blood Cell Microparticles: Clinical Relevance
}

\author{
Olivier Rubin Giorgia Canellini Julien Delobel Niels Lion Jean-Daniel Tissot \\ Service Régional Vaudois de Transfusion Sanguine, Epalinges, Switzerland
}

\section{Keywords}

Ageing · Microparticles · Red blood cells ·

Red blood cell concentrates · Transfusion

\section{Summary}

Microparticles are small phospholipid vesicles of less than $1 \mu \mathrm{m}$ released into the blood flow by various types of cells such as endothelial, platelet, white or red blood cells. They are involved in many biological and physiological processes including hemostasis. In addition, an elevated number of microparticles in the blood is observed in various pathological situations. In the context of transfusion, erythrocyte-derived microparticles are found in red blood cell concentrates. Their role is not elucidated, and they are considered as a type of storage lesion. The purpose of this review is to present recent data showing that erythrocyte-derived microparticles most likely play a role in transfusion medicine and could cause transfusion complications.

\section{Introduction}

Microparticles (MPs), also named microvesicle or ectosomes, are plasma membrane vesicles released into the blood flow by various types of cells such as platelets, red blood cells (RBCs), white blood cells, or endothelial cells [1]. MPs measure less than $1 \mu \mathrm{m}$. Most studies have shown that MPs are heterogeneous and vary in phospholipids, surface antigens, and protein content. They keep a subset of proteins derived from their parental cells as well as surface receptors allowing identification of their origin. MP release is a controlled process triggered by various stimuli including pro-apoptotic stimulation, shear stress, or damage [2]. A model of MP formation including

\author{
Schlüsselwörter \\ Alterung · Mikropartikel · Erythrozyten . \\ Erythrozytenkonzentrate $\cdot$ Transfusion
}

\section{Zusammenfassung}

Mikropartikel sind kleine $(<1 \mu \mathrm{m})$ Phospholipid-Vesikel, die von verschiedenartigen Zellen wie Endothelzellen, Thrombozyten sowie weißen und roten Blutkörperchen in den Blutstrom entlassen werden. Sie sind an vielen biologischen und physiologischen Prozessen einschließlich der Hämostase beteiligt. Des Weiteren wird eine erhöhte Anzahl an Mikropartikeln im Blut in verschiedenen pathologischen Situationen beobachtet. Im Zusammenhang mit Transfusionen sind von Erythrozyten abstammende Mikropartikel in Erythrozytenkonzentraten anzutreffen. Ihre Rolle ist ungeklärt, und sie werden als Lagerungsschaden betrachtet. Ziel dieser Übersichtsarbeit ist die Präsentation jüngster Daten, die zeigen, dass von Erythrozyten stammende Mikropartikel höchstwahrscheinlich eine Rolle in der Transfusionsmedizin spielen und zu Komplikationen führen können.

translocases, lipid rafts, various protein modifications, and irreversible membrane rearrangements has been established [3, 4] (fig. 1). The translocase named flippase maintains the phospholipid asymmetry of the membrane. Upon cell activation, the elevation of intracellular calcium concentration inhibits this enzyme and induces exposure of negatively charged phospholipids on the surface. Calcium also activates proteases such as calpain which cleaves the association between membrane proteins and cytoskeleton proteins. With additional lipid raft rearrangements the membrane becomes less stable, allowing formation and release of MPs [5, 6]. If MPs have been considered as cell fragments or 'dust' without any biological function [7], they are now recognized as being involved

\section{KARGER \\ Fax +497614520714 \\ Information@Karger.de}

www.karger.com (c) 2012 S. Karger GmbH, Freiburg $1660-3796 / 12 / 0395-0342 \$ 38.00 / 0$

Accessible online at: www.karger.com/tmb
Prof Jean-Daniel Tisso

Service Régional Vaudois de Transfusion Sanguine

Route de la Corniche 2

1066 Epalinges, Switzerland

Tel. + 4121 31465-89, Fax -78

jean-daniel.tissot@mavietonsang.ch 


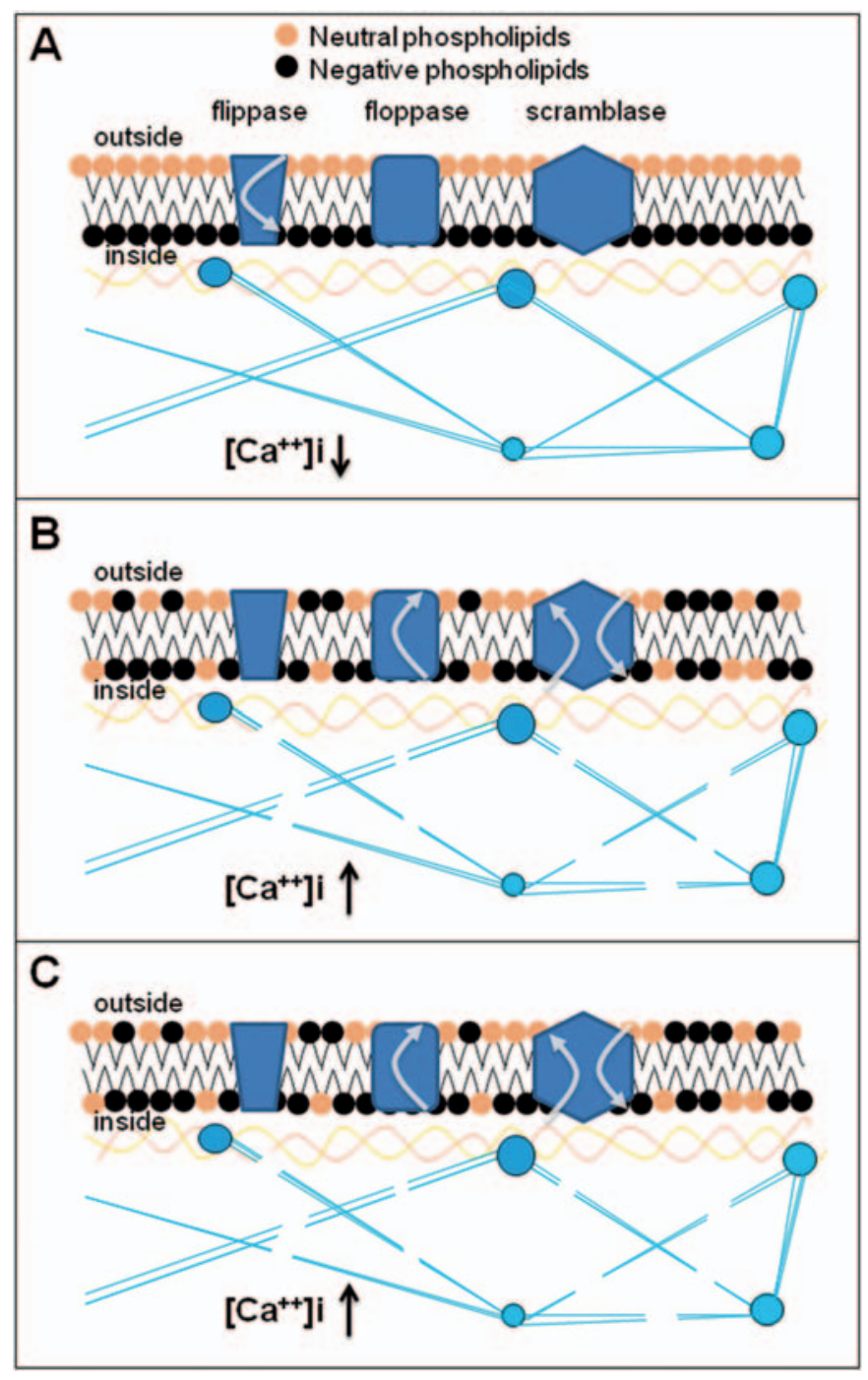

Fig. 1. Model of formation of microparticles. A Phospholipid organization is under the control of 3 enzymes: flippase, floppase, and scramblase. In resting cells, flippase internalizes negatively charged phospholipids and maintains the asymmetry of the phospholipid bilayer. Floppase and scramblase are inactive, and the cytoplasm calcium concentration is low. B Upon activation, intracellular calcium concentration increases, flippase is inhibited, while floppase and scramblase are activated. Floppase externalizes phosphatidylserine, a negative phospholipid, and scramblase translocates phospholipids non-specifically through the membrane resulting in the loss of phospholipid asymmetry. C Increased intracellular calcium also activates proteases that cleave the cytoskeleton; the membrane is less rigid and can bleb until formation and release of vesicles.

in a broad spectrum of biological activities including thrombosis, hemostasis $[1,8]$, and inflammation $[8,9]$. Although the presence of MPs in the blood is common in healthy individuals, an increase in the concentration of MPs in the plasma has been demonstrated in patients presenting with various pathological conditions such as thrombosis [1], cardiovascular disease [10], and sickle cell disease [11]. Their release could be thus considered as a hallmark of cellular alteration.

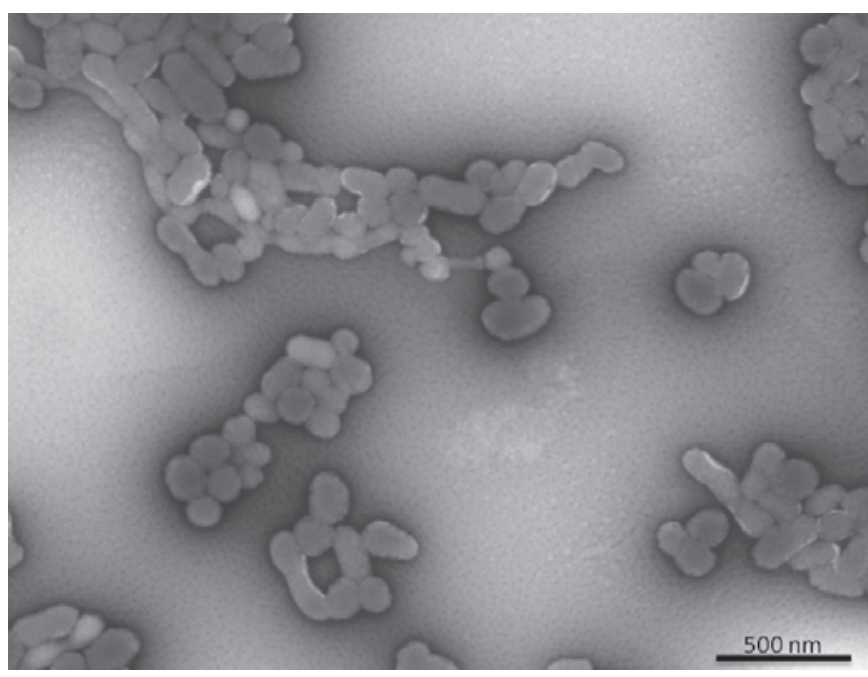

Fig. 2. Observation of erythrocyte-derived microparticles by electron microscopy (magnification $\times 22,000$ ).

\section{Erythrocyte-Derived Microparticles}

The main characteristics of erythrocytes-derived MPs (EMPs) are similar to those of MPs derived from other cells. Their size is generally more homogeneous and is around $0.15 \mu \mathrm{m}$ [12] (fig. 2). EMPs represent about 4-8\% of the total MPs [13] in platelet-rich plasma. As for other MPs, the physiological role of EMPs is not elucidated. In the context of transfusion medicine, they are considered as an RBC storage lesion, and thus may be involved in some effects described in patients transfused with blood stored for more that 21 (or 30) days. EMPs have been implicated in RBC senescence [14] and also proposed as playing a role in the apoptosis-like state [15]. During their 120-day lifespan, RBCs lose approximately $20 \%$ of their volume through vesicle emission whereas their hemoglobin concentration increases by $14 \%$ [16]. Vesiculation would be a means for RBCs to get rid of specific harmful agents such as denatured hemoglobin, C5b-9 complement attack complex, band 3 neoantigens, or immunoglobulin $\mathrm{G}$ that tend to accumulate during their lifespan [16, 17]. Through MP release, RBCs can clear these molecules while still viable, and thus prevent their early removal from the blood flow. In contrast, EMPs could promote removal of erythrocytes: CD47 is an integral membrane protein present on the erythrocyte surface, acting as a marker of self. Thanks to CD47, normal RBCs are recognized as self by macrophages (through their signal regulatory protein $\alpha$ ) and phagocytosis is inhibited. Senescent or damaged RBCs whose CD47 expression is reduced by selective shedding of EMPs would be eliminated by macrophages [18].

As for the RBC aging process, 2 main models resulting in microvesiculation have been proposed, the eryptosis model and the band 3 clustering model. The term eryptosis describes a similar mechanism of apoptosis occurring in nucleated cells in response to various stresses but applied to RBCs [15]. Influx 
of ionic calcium through nonspecific cation channels leads to activation of several enzymes such as calpain or scramblase. The triggers of this calcium intake are largely unknown, but alteration of nonspecific cation channels is often mentioned as a possible cause $[19,20]$. The band 3 clustering model links hemoglobin oxidation and hemichrome formation with dimerization of band 3 within the membrane through the creation of a disulfide bond. This dimerization induces a structural modification of the extracellular domains of band 3, thus creating a neoantigen that targets the RBC for removal through its recognition by naturally occurring antibodies $[21,22]$. Though it has not been demonstrated directly that the presence of the band 3 neoantigen can trigger microvesiculation, the enrichment in band 3 and band 3 dimers in microvesicles compared to their parent RBCs shows that microvesiculation may play a role in the elimination of band 3 neoantigens [14, 17]. Both models share a final outcome that is phosphatidylserine externalization on the RBC membrane and degradation of cytoskeleton proteins followed by modifications in the phosphorylation status of band 3 . This process gives sufficient membrane flexibility resulting in EMP formation and release.

$\mathrm{RBC}$ aging also occurs during storage. Even if RBC storage lesions appear multifaceted, they seem to follow a logical pathway leading to EMP generation. Progressive lack of energy resources induces depletion of antioxidant defenses, allowing oxidative lesions to occur and accumulate on RBC proteins, particularly the cytoskeleton [23] and band 3 loci. Senescent markers appear at these loci, making erythrocytes susceptible to be cleared by recipient macrophages once transfused. However, cytoskeleton alterations allow RBCs to eliminate such markers as well as other harmful components accumulating during storage thanks to the vesiculation process [16]. Interestingly, we have recently shown that RBC microvesiculation during blood banking takes part in the elimination of oxidized proteins: RBC microvesicles spontaneously released from banked erythrocytes are progressively enriched in carbonylated proteins during storage as compared to their parent cells [24]. This observation supports the hypothesis that microvesiculation may represent a mechanism allowing the elimination of deleterious components such as neoantigens or oxidized proteins.

\section{Clinical Aspects of Erythrocyte-Derived Microparticles}

Elucidating the role of EMPs represents a challenging field in various clinical situations, particularly in those characterized by hemolysis or endothelial activation such as sickle cell disease, paroxysmal nocturnal hemoglobinuria, acute graft-versus-host disease, and malaria infection.

In sickle cell disease, the polymerization of abnormal hemoglobin S affects RBC membrane stability, leading to erythrocyte sickling and vesiculation from spicules [25, 26]. EMP levels are elevated both in steady state and vaso-occlusive cri- sis, and correlate with the rate of intravascular hemolysis as well as the degree of coagulation activation $[11,27]$. Due to their hemoglobin content and phosphatidylserine exposure, EMPs may account for nitric oxide (NO) scavenging and procoagulant activity enhancement suggesting that more than half of the free plasma hemoglobin is contained in EMPs and could therefore significantly affect NO bioavailability [26, 27]. Phosphatidylserine-positive EMPs also have the capacity to generate thrombin $[11,27,28]$, probably through direct activation of FXI and binding of prothrombinase and tenase enzyme complexes on their surface [11]. EMP levels in sickle cell disease may define subclinical phenotypes with enhanced intravascular hemolysis and proneness to complications [29]. In addition, the follow-up of EMPs in the plasma may serve as biomarker for evaluating the efficacy of hydroxycarbamide treatment [27].

In paroxysmal nocturnal hemoglobinuria, the increase of EMPs or the proportion of different types of MPs is controversial [30-32]. Nevertheless, complement activation generates EMPs from glycosylphosphatidylinositol-deficient RBCs in a calcium-independent manner, and enhances their procoagulant activity in vitro $[32,33]$, proving that they may play a pathogenic role in the thrombotic profile of hemoglobinuria patients.

EMPs are increased in patients who develop acute graftversus-host disease after stem cell transplantation but not in those with infection or sepsis [34]. Therefore, EMPs may be regarded as a very helpful diagnostic tool to differentiate between these 2 complications in this clinical situation. The highest EMP count is observed in acute graft-versus-host disease associated with microangiopathy, suggesting an additional effect of mechanical destruction of RBCs on EMP release [34].

Authors have observed elevated levels of EMPs in human malaria, especially with Plasmodium falciparum and to a lesser extent with Plasmodium vivax and Plasmodium malariae [35]. In vitro, parasitized RBCs produce approximately 10 times more MPs than uninfected RBCs. However, in a surprising way, in vivo EMPs are derived mostly from normal erythrocytes [35].This may be explained by the release of hemin (an oxidative plasmodium heme) into the circulation during schizonte rupture, which triggers the production of EMPs from uninfected RBCs [36]. Thus, vesiculation may represent a parasite strategy to escape immune destruction by keeping the normal RBC membrane asymmetry. In patients suffering from malaria, EMP rates are also correlated with the degree of parasitemia and the severity of the infection.

\section{Methods of Erythrocyte-Derived Microparticle Analysis}

To date, even with the increasing interest in MPs, there are no standardized MP analysis methods, making any comparison 
between studies difficult. Several approaches are available such as electron microscopy, ELISA, proteomic methods, coagulation tests, and flow cytometry $[37,38]$. In a study carried out by us, flow cytometry analysis was performed with a precise number of fluorescent beads to determine the number of MPs in a sample, and fluorescent cell-specific antibodies. Briefly, samples were taken every 5-6 days from stored erythrocyte concentrates up to 50 days of storage. After dilution and antibody staining, samples were analyzed by flow cytometry. In this semi-quantitative study, an increase in the number of EMPs during storage from approximately $3.3 \pm 1.2$ $\times 10^{9} / 1$ on day 6 to approximately $20 \pm 10 \times 10^{9} / 1$ after 35 days of storage was observed [12]. We also tested the ability of EMPs to support coagulation: EMPs were isolated from 42-45 days stored erythrocyte concentrates by centrifugation; then, an increasing amount of EMPs was added to standard plasma and the prothrombin time (PT, Quick time) was measured. We observed that the EMPs in the plasma sample induced a significant decrease in PT [12].

\section{Potential Impact on the Coagulation Cascade and Transfusion Medicine}

As seen above, MPs including EMPs express phosphatidylserine. The presence of such negatively charged surfaces as well as calcium ions is required for the assembly of coagulation complexes such as tenase and prothrombinase, speeding up their association by around 1,000-fold for efficient hemostasis [39].It has been demonstrated that plateletderived MPs show 50 to 100 times more procoagulant activity than the platelets themselves [40]. At least in vitro, MP membranes support thrombin formation more efficiently than platelet membranes when corrected for unit of surface $[3,41]$. As they bear negatively charged membranes as well, EMPs could be involved in thrombin generation [11, 42]. To us, it appears that adding EMPs isolated from erythrocyte concentrates to plasma samples induces a significant decrease in PT (fig. 3). According to the literature, there are typically around $2 \times 10^{9} / 1$ platelet-derived MPs and $0.06 \times$ $10^{9} / 1$ EMPs in platelet-rich plasma $[2,43]$. It has been demonstrated that the number of EMPs increases during storage of erythrocyte concentrates [12]. Considering that the number of MPs in platelet-rich plasma reflects the number of MPs in the blood flow, and 'older' ( $>35$ days of storage) erythrocyte concentrates contain a high number of EMPs $\left(20 \pm 10 \times 10^{9} / 1\right)$, it may be hypothesized that the total number of EMPs in the recipient increases upon massive transfusion. Moreover, according to our preliminary results, EMPs support procoagulant activities. Taken together, this may suggest that EMPs increase the risk of a hypercoagulable state leading to thromboembolic complications. Thus, under certain circumstances, EMPs could take part in posttransfusion complications.

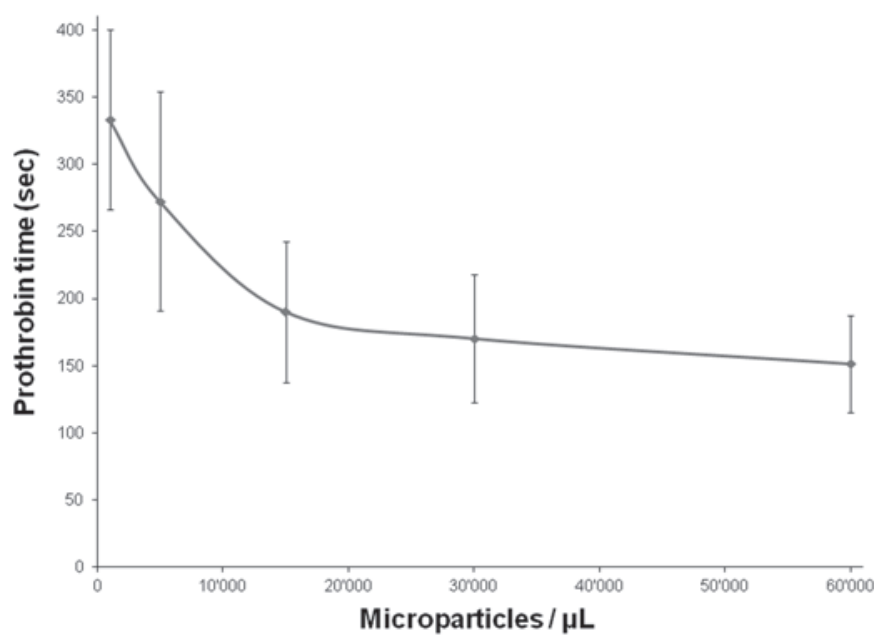

Fig. 3. Prothrombin time (PT) in relation to the amount of erythrocyte microparticles (EMPs) added to the assay. The more EMPs were added, the shorter the PT. EMPs were isolated from erythrocyte concentrates, and different amounts were added to citrated plasma. Calcium was added to start the reaction (but no tissue factor or thromboplastin). Data are presented as mean \pm standard deviation of 5 independent measurements.

\section{Potential Immunomodulary Effects of Red Blood Cell Microparticles}

Evidence has accumulated over the last few years converging to the fact that MPs are messengers as well as immunomodulators. Communication between cells relies on many different mechanisms that involve soluble mediators as well as cell-to-cell contact. In addition, MPs have been identified as mediators of distant communication between cells. The advantage is related to the fact that messages can be transmitted proteins, lipids, or even nucleic acids. By using MPs, messages are protected from the environment. What is the role of EMPs, and in particular of blood product-related EMPs? Are such EMPs related to the immunosuppressive properties associated with blood transfusion? Over the years, physicians have observed that blood transfusion is associated with immunosuppressive effects. Blood transfusion is associated with improved renal allograft survival after kidney transplantation and may be associated with reduced recurrence of Crohn's disease or with an increased risk of infection or cancer recurrence in transfused patients. Immunosuppressive efficiency of RBC transfusion has been clearly observed in patients receiving non-leukoreduced RBCs. The introduction of very efficient immunosuppressive drugs such as cyclosporine has stopped the interest of clinicians in evaluating the beneficial effects of erythrocyte transfusion in the context of solid organ transplantation. Nevertheless, the importance of leukocytes in the immunosuppressive efficiency of blood transfusions has been indirectly observed when infection rates were considered by comparing leukoreduced and non-leukoreduced RBCs, or auto- versus allo-trans- 
fusions. Therefore, well conducted clinical studies are needed in order to gain an insight in the mechanisms involved in the 'immunosuppressive' effects of blood transfusion, and to identify if the age of RBCs and/or EMPs plays a role in this context. The pioneering work of Schifferli et al. [44] has provided convincing elements allowing the identification of EMPs as major actors of immunosuppression after blood transfusion. Aged RBCs lose preferentially CR1 and DAF which accumulate on EMPs. These factors, as well as CD59, probably confer a resistance to complement attack to those EMPs that can bind to $\mathrm{C} 1 \mathrm{q}$ followed by $\mathrm{C} 3$ fixation as a result of complement activation [45]. EMPs are also characterized by a strong and quite long-lasting anti-inflammatory effect, evidenced when those EMPs are incubated with activated macrophages. In vitro, EMPs ingested by macrophages inhibited their activation by agents such as zymosan A or lipopolysaccharide [45]. Furthermore, the authors demonstrated that EMPs induced a major decrease in the release of various cytokines such as TNF- $\alpha$, IL-8, or IL-10. Taken together, these results clearly indicate that transfusion-related EMPs have immunosuppressive properties that may account for some of the undesirable effects related to the transfusion of stored RBCs [45].

\section{Future Perspective}

This review summarizes some of the most relevant studies allowing to better decipher the world of MPs. Even if the knowledge on the roles, structure, and function of MPs as well as on EMPs has dramatically increased over the last few years, efforts are still mandatory in order to better understand the storage lesions of both platelet and erythrocyte concentrates in blood banks. These efforts should allow us to provide more standardized blood products and ameliorate the quality of the various blood products that are delivered every day to patients. Finally, and because many new processing procedures (pathogen reduction, automation, modification of aphaeresis and machines, changes in storage solutions etc.) are being developed by various companies, a strict evaluation of the biochemical and structural composition of blood products should be implemented. This, in association with well-conducted clinical studies, will be part of the future of modern transfusion medicine.

\section{Disclosure Statement}

The authors declare no conflict of interest.

\section{References}

1 Diamant M, Tushuizen ME, Sturk A, Nieuwland R: Cellular microparticles: new players in the field of vascular disease? Eur J Clin Invest 2004;34:392401.

2 Simak J, Gelderman MP: Cell membrane microparticles in blood and blood products: potentially pathogenic agents and diagnostic markers. Transfus Med Rev 2006;20:1-26.

>3 Morel O, Toti F, Hugel B, Bakouboula B, CamoinJau L, Dignat-George F, Freyssinet JM: Procoagulant microparticles - disrupting the vascular homeostasis equation? Arterioscler Thromb Vasc Biol 2006;26:2594-2604.

$\checkmark 4$ Hugel B, Carmen M, Martinez MC, Kunzelmann C, Freyssinet JM: Membrane microparticles: two sides of the coin. Physiology 2005;20:22-27.

$\checkmark 5$ An XL, Guo XH, Sum H, Morrow J, Gratzer W, Mohandas N: Phosphatidylserine binding sites in erythroid spectrin: location and implications for membrane stability. Biochemistry 2004:43:310-315.

6 Manno S, Takakuwa Y, Mohandas N: Identification of a functional role for lipid asymmetry in biological membranes: phosphatidylserine-skeletal protein interactions modulate membrane stability. Proc Natl Acad Sci U S A 2002;99:1943-1948.

$\checkmark 7$ Wolf P: Nature and significance of platelet products in human plasma. Br J Haematol 1967;13:269288.

8 Greenwalt TJ: The how and why of exocytic vesicles. Transfusion 2006;46:143-152.

$\checkmark$ Schifferli JA: Microvesicles are messengers. Semin Immunopathol 2011;33:393-394.

10 VanWijk MJ, VanBavel E, Sturk A, Nieuwland R: Microparticles in cardiovascular diseases. Cardiovasc Res 2003;59:277-287.
1 Van Beers EJ, Schaap MC, Berckmans RJ, Nieuwland R, Sturk A, van Doormaal FF, Meijers JC, Biemond BJ: Circulating erythrocyte-derived microparticles are associated with coagulation activation in sickle cell disease. Haematologica 2009;94:1513-1519.

12 Rubin O, Crettaz D, Canellini G, Tissot JD, Lion $\mathrm{N}$ : Microparticles in stored red blood cells: an approach using flow cytometry and proteomic tools. Vox Sang 2008;95:288-297.

13 Shah MD, Bergeron AL, Dong JF, Lopez JA: Flow cytometric measurement of microparticles: pitfalls and protocol modifications. Platelets 2008;19:365372.

14 Bosman G, Werre JM, Willekens FLA, Novotny VMJ: Erythrocyte ageing in vivo and in vitro: structural aspects and implications for transfusion. Transfus Med 2008;18:335-347.

15 Foller M, Huber SM, Lang F: Erythrocyte programmed cell death. IUBMB Life 2008;60:661-668.

16 Willekens FLA, Werre JM, Groenen-Dop YAM, Roerdinkholder-Stoelwinder B, de Pauw B, Bosman G: Erythrocyte vesiculation: a self-protective mechanism? Br J Haematol 2008;141:549-556.

17 Bosman G, Lasonder E, Luten M, RoerdinkholderStoelwinder B, Novotny VMJ, Bos H, De Grip WJ: The proteome of red cell membranes and vesicles during storage in blood bank conditions. Transfusion 2008:48:827-835.

18 Stewart A, Urbaniak S, Turner M, Bessos H: The application of a new quantitative assay for the monitoring of integrin-associated protein CD47 on red blood cells during storage and comparison with the expression of CD47 and phosphatidylserine with flow cytometry. Transfusion 2005;45:1496-1503.

19 Lang F, Gulbins E, Lerche H, Huber SM, Kempe DS, Foller M: Eryptosis, a window to systemic disease. Cell Physiol Biochem 2008;22:373-380.
20 Low PS, Willardson BM, Mohandas N, Rossi M, Shohet S: Contribution of the band 3-ankyrin interaction to erythrocyte-membrane mechanical stability. Blood 1991;77:1581-1586.

21 Kay MMB, Goodman SR, Sorensen K, Whitfield CF, Wong P, Zaki L, Rudloff V: Senescent cell antigen is immunologically related to band-3. Proc Natl Acad Sci U S A 1983;80:1631-1635.

22 Arese P, Turrini F, Schwarzer E: Band 3/complement-mediated recognition and removal of normally senescent and pathological human erythrocytes. Cell Physiol Biochem 2005;16:133-146.

-23 Kriebardis AG, Antonelou MH, Stamoulis KE, Economou-Petersen E, Margaritis LH, Papassideri IS: RBC-derived vesicles during storage: ultrastructure, protein composition, oxidation, and signaling components. Transfusion 2008;48:1943-1953.

24 Delobel J, Prudent M, Rubin O, Crettaz D, Tissot JD, Lion N: Subcellular fractionation of stored red blood cells reveals a compartment-based protein carbonylation evolution. J Proteomics 2012; DOI: 10.1016/j.prot.2012.05.004.

25 Allan D, Limbrick AR, Thomas P, Westerman MP Release of spectrin-free spicules on reoxygenation of sickled erythrocytes. Nature 1982;295:612-613.

26 Reiter CD, Wang X, Tanus-Santos JE, Hogg N, Cannon RO 3rd, Schechter AN, Gladwin MT: Cellfree hemoglobin limits nitric oxide bioavailability in sickle-cell disease. Nat Med 2002;8:1383-1389.

27 Westerman M, Pizzey A, Hirschman J, Cerino M, Weil-Weiner Y, Ramotar P, Eze A, Lawrie A, Purdy G, Mackie I, Porter J: Microvesicles in haemoglobinopathies offer insights into mechanisms of hypercoagulability, haemolysis and the effects of therapy. Br J Haematol 2008;142:126-135. 
28 Horne MK 3rd, Cullinane AM, Merryman PK, Hoddeson EK: The effect of red blood cells on thrombin generation. Br J Haematol 2006;133:403-408.

29 Kato GJ, McGowan V, Machado RF, Little JA, Taylor Jt, Morris CR, Nichols JS, Wang X, Poljakovic M, Morris SM Jr, Gladwin MT: Lactate dehydrogenase as a biomarker of hemolysis-associated nitric oxide resistance, priapism, leg ulceration, pulmonary hypertension, and death in patients with sickle cell disease. Blood 2006;107:2279-2285.

- 30 Hugel B, Socie G, Vu T, Toti F, Gluckman E, Freyssinet JM, Scrobohaci ML: Elevated levels of circulating procoagulant microparticles in patients with paroxysmal nocturnal hemoglobinuria and aplastic anemia. Blood 1999;93:34513456.

31 Simak J, Holada K, Risitano AM, Zivny JH, Young NS, Vostal JG: Elevated circulating endothelial membrane microparticles in paroxysmal nocturnal haemoglobinuria. Br J Haematol 2004;125:804-813.

32 Kozuma Y, Sawahata Y, Takei Y, Chiba S, Ninomiya H: Procoagulant properties of microparticles released from red blood cells in paroxysmal nocturnal haemoglobinuria. Br J Haematol 2011;152:631-639.

33 Whitlow M, Iida K, Marshall P, Silber R, Nussenzweig V: Cells lacking glycan phosphatidylinositol-linked proteins have impaired ability to vesiculate. Blood 1993;81:510-516.

-34 Rank A, Nieuwland R, Toth B, Pihusch V, Delker R, Hiller E, Kolb HJ, Pihusch $\mathrm{R}$ : Microparticles for diagnosis of graft-versus-host disease after allogeneic stem transplantation. Transplantation 2011;92:244-250.

-35 Nantakomol D, Dondorp AM, Krudsood S, Udomsangpetch R, Pattanapanyasat K, Combes V, Grau GE, White NJ, Viriyavejakul P, Day NP, Chotivanich K: Circulating red cell-derived microparticles in human malaria. J Infect Dis 2011; 203:700-706.

36 Omodeo-Sale F, Monti D, Olliaro P, Taramelli D: Prooxidant activity of betahematin (synthetic malaria pigment) in arachidonic acid micelles and phospholipid large unilamellar vesicles. Biochem Pharmacol 2001;61:999-1009.

37 Rubin O, Crettaz D, Tissot JD, Lion N: Pre-analytical and methodological challenges in red blood cell microparticle proteomics. Talanta 2010;82:1-8.

38 Jy W, Horstman LL, Jimenez JJ, Ahn YS: Measuring circulating cell-derived microparticles. J Thromb Haemost 2004;2:1842-1851.

39 Kini RM: Structure-function relationships and mechanism of anticoagulant phospholipase a(2) enzymes from snake venoms. Toxicon 2005;45:1147-1161.

40 Sinauridze EI, Kireev DA, Popenko NY, Pichugin AV, Panteleev MA Krymskaya OV, Ataullakhanov FI: Platelet microparticle membranes have 50-to 100 -fold higher specific procoagulant activity than activated platelets. Thromb Haemost 2007;97:425-434.

41 Furie B, Furie BC: Mechanisms of disease: mechanisms of thrombus formation. N Engl J Med 2008;359:938-949.

42 Chung SM, Bae ON, Lim KM, Noh JY, Lee MY, Jung YS, Chung JH: Lysophosphatidic acid induces thrombogenic activity through phosphatidylserine exposure and procoagulant microvesicle generation in human erythrocytes. Arterioscler Thromb Vasc Biol 2007;27:414-421.

43 Lacroix R, Robert S, Poncelet P, Kasthuri RS, Key NS, Dignat-George F, Workshop IS: Standardization of platelet-derived microparticle enumeration by flow cytometry with calibrated beads: results of the International Society on Thrombosis and Haemostasis SSC Collaborative workshop. J Thromb Haemost 2010; 8:2571-2574.

44 Sadallah S, Eken C, Schifferli JA: Ectosomes as modulators of inflammation and immunity. Clin Exp Immunol 2011;163:26-32.

45 Sadallah S, Eken C, Schifferli JA: Erythrocyte-derived ectosomes have immunosuppressive properties. J Leukoc Biol 2008;84:1316-1325. 